\title{
Congratulations to Professor Pavel Mach on the occasion of his 60th birthday
}

\author{
Ondrej Kysel
}

Received: 8 April 2012 /Accepted: 17 April 2012 /Published online: 22 May 2012

(C) Springer-Verlag 2012

Omnia disce, videbis postea nihil esse superfluum

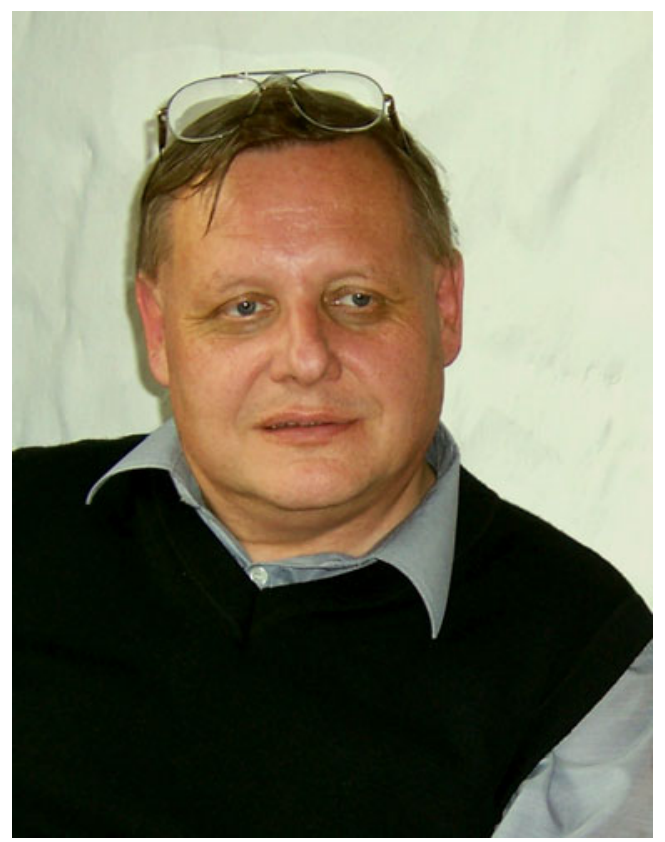

Pavel Mach was born on 30 March 1952 in the Slovak city of Ružomberok, which lies in a beautiful region in the heart of Slovakia. In 1976, he finished his Masters degree in Chemical Engineering at the Slovak Technical University in Bratislava, specializing in physical chemistry and chemical physics with outstanding diploma results. His research career continued with his doctoral studies at the Slovak Academy of Sciences

O. Kysel ( $\square)$

Department of Chemistry, Matej Bel University,

Banská Bystrica, Slovakia

e-mail: Ondrej.Kysel1@gmail.com
(SAS) in the Department of Chemical Physics of the Polymer Institute in Bratislava. His original scientific contribution during his $\mathrm{PhD}$ years was devoted to quantum-chemical elucidation of the unique inhibition-catalytic free radical mechanism of a new generation of a very efficient class of photostabilizers of synthetic polymers (like PP and PE) sterically hindered secondary amines (HALSes) - which have been massively exploited to date. After a successful thesis defense in 1983, he continued this research supplemented by theoretical inclusion of polar media effects through the polarizable continuum model (PCM). The development of this solvent model, now used extensively in chemical, biochemical and physical research laboratories all over the world, has its roots in the late 1970s in the Laboratory of Chemical Physics of Polymer Institute of SAS, and now has thousands of SCI citations. Pavel Mach made many contributions to the application of the theoretical PCM model.

In 1992, he moved to the Laboratory of Biophysics and Chemical Physics at the Faculty of Mathematics and Physics at Comenius University, Bratislava, and in 1995 he became Associate Professor. Here, alongside his devotion to the education of university students, he made many contributions to topical research fields in chemical physics, such as the development of Brillouin-Wigner perturbation theory and its computer applications to atomic and molecular systems, computer modeling of the spectral and thermodynamics properties of charge-transfer inter- and intra-molecular systems including those used in molecular biology. He is also actively engaged in implementation of quantum-mechanical methods to elucidate the formation of products from the fragmentation of biologically interesting ions in MS spectroscopy, as well as the crystal structures of chemical compounds studied by inelasting neutron scattering.

In the above-mentioned fields, Pavel Mach has contributed as author and coauthor of 80 original scientific papers 
published in internationally respected peer-reviewed journals with an unbelievable number of almost 100 coworkers! His scientific contributions are appreciated and recognized by many colleagues all over the world and he has deservedly contributed to the international prestige of Slovak theoretical chemistry and chemical physics. Pavel has received many scientific awards; however, he appreciates much more the quiet spirit of research and devoted people around him than the golden flash of medals.

Without doubt, Pavel Mach belongs to the group of outstanding Slovak scientists not only because of his high and honest professional reputation but also because of his highly qualified knowledge of a broad spectrum of chemical, physical and biological fields. His personal priority is certainly not own scientific prestige but rather to altruistically help others, especially young adepts of natural sciences, to love and to become devoted to scientific truth, which certainly benefits mankind.

I am proud and glad to have been, for many years, Pavel's coworker and close friend with whom I have shared the priceless spirit of discovery.

On the occasion of his 60th birthday, I sincerely congratulate Pavel Mach in the name of his many Slovak scientific friends, coworkers, colleagues, students and also, I dare to say, on behalf of so many friends and coworkers from many countries all over the world.

Long live Pavel!

Acknowledgments I very much acknowledge the editors of the Journal of Molecular Modeling for allowing publication of this tribute in this special issue. 